\title{
THE INDIAN AGRICULTURAL RESEARCH INSTITUTE
}

$\mathrm{T}$ HE Indian Agricultural Research Institute has been accorded the status of a university with power to confer the degrees of M.Sc. and Ph.D. in all the important aspects of agricultural science. The new Postgraduate School was formally inaugurated on October 6, 1958, by Shri Ajit Prasad Jain, Minister for Food and Agriculture in the Government of India.

The Institute is popularly known as the Pusa Institute, after a small village called Pusa in Bihar, where it was first established as the Imperial Agricultural Institute in 1905 with a gift of $£ 30,000$ from Mr. Henry Phipps, an American philanthropist. It has now developed into a centre of considerable size, providing facilities for training and research in almost all the important branches of agricultural science. These various activities are carried out by its seven Divisions, covering, respectively, agronomy, botany, mycology and plant pathology, entomology, horticulture, soil science and agricultural chemistry, and agricultural engineering, under the over-all supervision of the director, Dr. B. P. Pal. All the Divisions are housed separately in spacious buildings, furnished with modern equipment, and each is staffed with teachers and specialists in the appropriate field.

The Institute has inherited a great tradition of agricultural research and education, going back to the work of Leather in agricultural chemistry, of Butler on fungi and fungal diseases of plants, of Maxwell-Lefroy and Fletcher in cataloguing and combating insect pests, of the Howards in breeding the early 'Pusa' wheats, and of Venkataraman in breeding Coimbatore canes. High among the recent achievements are the breeding of NP ('New Pusa') wheats, of which NP 710 and NP 718 combine considerable resistance to rust with high resistance to loose smut. An outstanding success is the breeding of NP 809 wheat for the hills, uniting resistance to the three rusts. Among other contributions of note are the building up of a fine milch herd of the Sahiwal breed; the construction of schedules for the control of some important diseases of sugar cane; and the improvement of techniques of breeding parasites for the biological control of some insect pests of crop plants.

The Library, which receives more than a thousand periodicals and possesses almost all the important publications on agricultural science, is considered to be the best agricultural library in the East, and caters for the needs of agricultural scientists all over India. Other assets of the Institute include collections of varieties of crop plants from which the plant breeder can select the genes for his breeding work; the National Collection of Insects; the Herbarium Cryptogramme Indiae Orientalis, one of the best assemblages of fungi in the East; and the Indian Type Culture Collection.

The archives of the Institute show that, from its inception in 1905, it was meant to be a central organization of postgraduate teaching. In 1923, two-year postgraduate courses leading to the award of the diploma of the associateship of the Imperial Agricultural Research Institute were instituted, offering limited facilities to students in specialized fields, without, however, offering any definite courses. In 1945 the system of training was thoroughly reorganized, courses and syllabuses were prescribed and a system of examinations introduced. The diploma awarded is comparable with the M.Sc. degree of a university.

The present decision to provide the Institute with a Postgraduate School is a natural step in fulfilling the objects which the planners of the Institute had in view. The recommendations of the Indo-American team on agricultural research and education were instrumental in giving shape to the ideals of its founders. The Postgraduate School, which will mainly be responsible for earrying out the teaching programme, has come into existence with the generous aid of the Rockefeller Foundation. The aim is to train leaders for the programme to improve agricultural technology in India.

The students will have a large number of courses to choose from, including crop husbandry, soil and water management, agricultural extension; plant breeding and genetics, cytogenetics and plant physiology ; taxonomy, ecology, toxicology, parasitology, and physiology of insects; pomology, olericulture, fruit and vegetable preservation; mycology and plant pathology; soil science and agricultural chemistry; and agricultural engineering. Courses in experimental statistics will be offered in co-operation. with the Indian Council of Agricultural $R_{\theta}$. search.

Provision has been made, for the present, for admitting each year up to one hundred students for the M.Sc. degree and fifty students for the Ph.D. degree.
B. P. PAL

\section{THE EMPLOYEE'S POINT OF VIEW}

$T^{N}$ the middle nineteen-thirties, the National Institute of Industrial Psychology was asked by a large and well-known company to help in solving a staffing problem. The company's employment policy was progressive, and reasons for a very high rate of leaving were obscure. It was arranged to take the (then) unorthodox step of inviting employees to come, in confidence, to the Institute's investigator to give suggestions for improvements in their working conditions or to mention features of them which they would like to see changed. These interviews had far-reaching results; from their success stems a technique which has been fruitfully applied in the United Kingdom to the diagnosis of many working situations, in industry, shops and offices, hospitals and voluntary organizations. It brings to the study of people in their working environment, and particularly in relation to difficulties they experience, a special combination of human understanding with scientific discipline.

The core of the method consists in confidential, undirected interviews with a sample of employees of all levels: the interviews are conducted by an impartial investigator who is not on the staff of the 
organization, and in whose freedom from bias all concerned may have confidence.

After many years of experience, during which the Institute's technique in this work was progressively improved, there was developed a standard system for classifying subjects raised in such interviews. It provided convenient, ordered categories to which could be assigned remarks relating to any aspect of working life, and it was intended to facilitate future study of the accumulating material.

Dr. Isabel Blain has now made a pilot study of results collected and reported by these methods within a recent two-year period (Comments on the Job. Nat. Inst. Indust. Psych., Rep. 13, 1958). The data came from six firms; all were manufacturing companies, and apparently had little in common save their concern over some aspect of their organization or operation, to improve which they had invited the Institute's help. They differed in size of pay-roll, form of ownership, geographical position, age, history and tradition, arrangements of hours and shifts, degree of trades union influence, amenities, welfare provisions, and physical working conditions. The purpose of the study was to see whether, in spite of these differences, similarities would be found in the spontaneous remarks made by 1,678 factory staff and operatives.

Some of the salient points which emerged showed a surprising degree of similarity in each of the firms investigated. Thus, planning and control procedures, timing, time standards and time allowances, maintenance and stores arrangements were common topics of complaint.

Practice and policy relating to training, promotion and transfer were criticized, sometimes through ignorance, sometimes justifiably, due to acknowledged defects; but there were also instances where approval was expressed of company action in these fields.

On matters of pay, men complained more frequently than women about the amounts earned; but the greatest body of critical comment related to financial incentive schemes and to differentials.

In every company there were remarks about the inadequate definition of responsibility and authority ; similarly, poor liaison between shifts or between departments was commonly mentioned; there were also frequent complaints about lack of information from management.

\title{
PATTERN OF SYNTHESIS OF DEOXYRIBONUCLEIC ACID IN BACILLUS CEREUS GROWING SYNCHRONOUSLY OUT OF SPORES
}

\author{
By Dr. I. ELIZABETH YOUNG and Prof. PHILIP C. FITZ-JAMES \\ Department of Bacteriology and Immunology and Department of Biochemistry, University of Western Ontario
}

$\mathrm{V}^{\mathrm{s}}$ ARYING degrees of synchrony of bacterial cell division have been achieved by prior subjection of the cell population to chilling ${ }^{1}$, cycles of chilling and was ming ${ }^{2-5}$, to starvation followed by replenishment $t^{6,7}$ and by separation of the cells into a homogeneous group by fractional filtration ${ }^{8}$. In all such cases synchrony "is initiated by a phase of recovory from imposed stress and unbalance"s and in some there is evidence that interference with the synthesis of deoxyribonucleic acid is the critical feature ${ }^{9}$. It has already been shown that the initial duplication of the chromatin body of synchronously germinated. spores (B. megaterium and $B$. cereus) is accompanied by a linear synthesis of deoxyribonucleic acid ${ }^{10}$. But, as no cellular division occurred prior to these doublings, no data were available regarding the relationship between synthesis of deoxyribonucleic acid and the normal division cycle. Such has now been obtained from a combined cytological and chemical study of $B$. cereus in which synchronous germination of spores was followed by two successive periods of synchronous cell division.

Uniform batches of spores were harvested from either the agar medium of Howie and Cruickshank ${ }^{11}$ or a fluid medium (glutamine-casein-yeast) developed for the study of synchronous spore formation $^{12}$. Spores were washed free of all traces of cell debris by eight cycles of differential centrifugation from water. Sporo counts were made on appropriate dilutions of the final clean suspension.

The germination medium used was similar to that already described ${ }^{10}$. Spores sufficient to give a final concentration of $0.6 \times 10^{8} / \mathrm{ml}$, were inoculated below the surface of the medium, which had been warmed to $37^{\circ} \mathrm{C}$. Aeration by shaking was begun immediately, and after 3 min. a drop of tri- $n$-butyl citrate was added to counteract foaming.

Cells centrifuged from rapidly chilled samples were washed in quick succession with ice-cold bicarbonate buffer, 50 per cent ethanol in buffer and absolute ethanol. Following disruption of the cells with glass beads (Ballotini No. 12) in the Mickle ${ }^{13}$ tissue disintegrator, deoxyribonucleic acid was extracted by the Schmidt and Thannhauser procedur $\theta^{14}$ and estimated by the Dische reaction ${ }^{15}$. At each time period of analysis, the living cells were examined in the phase-contrast microscope and osmium-fixed. impression smears stained by an azure $A$-Feulgen procedure ${ }^{16}$ were examined under the light microscope.

In order to obtain good synchrony through the first two divisions of the emergent cells, it was considered necessary that 95 per cent of the spores lose refractility and stain deeply with crystal violet (that is, begin germination) during a 1-min. interval commencing 1 1 -2 min. following inoculation. Occasionally this degree of synchrony could be obtained with fresh spores. In such cases prior activation with sublethal heating ${ }^{17}\left(70^{\circ} \mathrm{C}\right.$. for $15 \mathrm{~min}$.) did not improve the degree of synchrony. However, heat treatment usually decreased the response time of germination and made synchrony more readily attainable. It should be stressed that the subsequent pattern of synthesis of deoxyribonucleic acid was the same whether or not the spores were activated by heat. 